\title{
Intersubjetividade e idealismo transcendental \\ em Husserl
}

\author{
Intersubjectivity and transcendental idealism in
}

Husserl

SCHEILA CRISTIANE THOMÉa

\section{Resumo}

O objetivo central deste artigo é o de discutir se Husserl de fato consegue apresentar uma compreensão derradeira da intersubjetividade de um modo estritamente transcendental e assim se Husserl pôde ou não superar definitivamente toda forma de solipsismo. A posição que pretendo defender é que Husserl consegue apresentar uma compreensão coerente de intersubjetividade entendida em termos transcendentais a partir de um aprofundamento dos processos de redução transcendental. Será defendido também que a explicitação do estatuto transcendental da intersubjetividade não se contrapõe de maneira alguma ao idealismo transcendental fenomenológico proposto por Husserl, ao contrário, será mostrado que a compreensão do estatuto transcendental da intersubjetividade contribui para uma melhor e mais adequada caracterização do que é o campo do idealismo transcendental fenomenológico em Husserl. Para realização de tal empreitada será tomado como objeto de análise, em especial, os textos das Meditações cartesianas IV e V.

Palavras-chave: Intersubjetividade. Idealismo transcendental. Redução fenomenológica. Emparelhamento (Paarung).

\section{Abstract}

The central aim of this article is to discuss whether Husserl could effectively present an ultimate understanding of intersubjectivity in a strictly transcendental way and thus

\footnotetext{
a Universidade Federal de São Paulo, Guarulhos, SP, Brasil. Doutora em Filosofia, e-mail: thome.scheila@gmail.com
} 
whether Husserl was able to definitively overcome any form of solipsism. The position that $I$ intend to defend is that Husserl is able to present a coherent understanding of transcendentally understood intersubjectivity from a deepening of transcendental reduction processes. It will also be argued that the explication of the transcendental status of intersubjectivity does not in any way contradict the phenomenological transcendental idealism proposed by Husserl. On the contrary, it will be shown that the understanding of the transcendental status of intersubjectivity contributes to a better and more adequate characterization of what is the field of phenomenological transcendental idealism in Husserl. In order to carry out this work, the texts of Cartesian Meditations IV and V will be taken as the object of analysis.

Keywords: Intersubjectivity. Transcendental Idealism. Phenomenological Reduction. Pairing (Paarung).

\section{Introdução}

Sabe-se que nas últimas décadas de sua vida Husserl não cansou de apresentar a sua fenomenologia como uma nova forma de idealismo transcendental, não medindo esforços para explicitar em que consiste a sua proposta de idealismo e no que este se diferencia dos idealismos transcendentais clássicos. No entanto, as vozes dos seus diversos interlocutores não deixam de repetidas vezes acusá-lo de cair inevitavelmente em um solipsismo, mesmo que estritamente transcendental. Já alguns antigos discípulos de Husserl, como Ingarden, por exemplo, viram na virada idealista e transcendental do pensamento de Husserl, promovida já desde Ideias I, "O abandono de uma visão de um sóbrio realismo para a assunção um idealismo inconsequente" (INGARDEN, 1975, p. 5). O próprio Husserl, tendo adotado o idealismo transcendental, tornou-se cada vez mais consciente do problema levantado em relação à intersubjetividade, colocando para si mesmo a pergunta sobre como, desde uma perspectiva idealista, reconheço a existência de Outros egos como sujeitos transcendentais. Mesmo confrontado com as dificuldades de tal reconhecimento, Husserl, no entanto, não abandonou a perspectiva do idealismo transcendental. Em vez disso, ele procurou sua solução buscando aprofundar o sentido do idealismo que ele desenvolveu.

Assim, para Husserl, se, por um lado, é a perspectiva idealista transcendental de seu pensamento que traz à tona o problema do solipsismo, por outro lado, somente uma explicitação aprofundada desta forma de idealismo é que pode resolver este problema. Desde modo, concordamos aqui com a leitura de James Mensch (1988), 
que afirma que Husserl pôde, de fato, resolver em si mesmo, no interior da sua proposta de idealismo transcendental, o problema do reconhecimento de Outros egos transcendentais. Segundo Mensch, tal resolução é tornada possível mediante uma realização plena do processo de redução fenomenológica.

Assim, para Husserl, a consideração de que o idealismo transcendental pode resolver em si mesmo o problema do reconhecimento dos Outros envolve realmente outra consideração: o idealismo transcendental acaba por descobrir essa subjetividade 'primordial', a priori, quando segue seu próprio método até o fim. Este método, o da redução fenomenológica, permite fundar nossos atos de reconhecimento dos Outros, ao descobrir o fundamento de todas nossas relações aos Outros (MENSCH, 1988, p. 1).

No entanto, se direcionarmos o olhar para as diversas leituras sobre a questão da intersubjetividade transcendental em Husserl, realizadas por intérpretes contemporâneos e posteriores a Husserl, observa-se uma constante acusação de um fracasso de Husserl em sua tentativa de compreender a intersubjetividade em termos estritamente transcendentais, o que definiria o pensamento husserliano como um pensamento propriamente solipsista. Esse é o diagnóstico, por exemplo, que Sartre em O Ser e o Nada faz de Husserl ao nos dizer que os argumentos oferecidos por Husserl nas Meditações cartesianas apenas apresentam um "paralelismo de egos empíricos” e nunca de egos transcendentais (SARTRE, 1997, p. 304). Também Schütz argumenta que o emparelhamento de egos proposto por Husserl em Meditações cartesianas, que revelaria, segundo Husserl, o reconhecimento entre egos transcendentais, é, para Schütz $(1966 ; 1973)$, apenas um reconhecimento entre egos empíricos, mundanos. Mesmo Merleau-Ponty (1994; 1991; 2006) que viu nos conceitos husserlianos de corpo próprio (Leib) e natureza primordial o ponto de partida para a construção de sua própria fenomenologia, aponta para certo "solipsismo ontológico de direito" ao qual o pensamento de Husserl ainda recairia ao considerar o eu puro o fundamento último por meio do qual "outrem" só pode surgir como uma manifestação acoplante (SILVA, 2009, p. 233).

Será, portanto, o objetivo deste artigo discutir, a partir das leituras críticas de seus principais intérpretes, se Husserl de fato consegue apresentar uma compreensão derradeira da intersubjetividade de um modo estritamente transcendental e assim se Husserl pôde ou não superar definitivamente toda forma de solipsismo. A posição que pretendo defender é que Husserl consegue apresentar uma compreensão coerente 
da intersubjetividade entendida em termos transcendentais a partir de um aprofundamento dos processos de redução transcendental. Assim, acompanhando os textos husserlianos, vê-se que um reconhecimento de Outros egos em um nível transcendental só se torna possível a partir de uma realização plena da redução fenomenológica, uma redução aos estratos mais profundos de toda constituição de quaisquer objetos. Portanto, para Husserl, é somente uma explicitação da esfera derradeira da constituição, descoberta pela realização radical do exercício da redução fenomenológica, que permite uma compreensão do estatuto propriamente transcendental da intersubjetividade. Segundo Husserl é somente ao pensar a intersubjetividade transcendental a partir do solo derradeiro da subjetividade originária que se pode afastar, de uma vez por todas, o fantasma do solipsismo que paira em torno de sua fenomenologia. Porém, antes de nos determos em analisar em que consiste o estatuto da intersubjetividade transcendental, faz-se necessário primeiro uma análise sobre em que consiste, de modo geral, a tese do idealismo transcendental proposta por Husserl e o que no interior dela poderia sugerir a existência de um suposto solipsismo, apontando em seguida para o modo como Husserl procurou superar tal problema.

\section{O estatuto do idealismo transcendental fenomenológico de Husserl}

O início da Quarta Meditação cartesiana já anuncia o que vem a ser o núcleo central do idealismo transcendental fenomenológico de Husserl: “os objetos são para mim, e são para mim o que são apenas como objetos de consciência efetiva e possível" (HUSSERL, 2013, p. 103; HUSSERL, 1950, p. 99). Tal passagem parece já delinear aquilo que consistirá a tese central do idealismo transcendental husserliano: a dependência ontológica e epistemológica do mundo em sua correlação com a consciência.

As considerações de Roman Ingarden (1975) nos ajudam a estabelecer uma primeira compreensão sobre o idealismo de Husserl, esclarecendo primeiramente em que consiste a controvérsia idealismo e realismo:

a controvérsia entre realistas e idealistas em relação à existência do mundo real não é sobre a questão de saber se o mundo real, o mundo material em particular, existe em geral. Ambos 
reconhecem tal existência. A controvérsia é antes 'sobre o modo de existência do mundo e qual é a sua relação existencial com atos de consciência em que os objetos pertencentes ao mundo são conhecidos' (INGARDEN, 1975, p. 5).

Para o realista, esse modo de existência é tal que os objetos do mundo são considerados como tendo suas próprias qualidades inerentes a si mesmos. Um objeto possui uma essência independente composta de tais qualidades. Os protestos idealistas são contra essa "absolutização" realista do mundo. Esse protesto significa uma oposição à ideia de que o mundo e seus objetos sejam realidades existentes em si mesmas, sejam “objetos em si”, objetos cuja existência é pensada de um modo separado e independente em relação à consciência subjetiva.

Para Husserl, no entanto, os objetos e o mundo como um todo só podem ser pensados como correlatos da consciência, como objetidades constituídas pelos diversos modos de constituição intencional realizados mediante atos da consciência. Os objetos são para Husserl, no contexto de Meditações cartesianas, a unidade e identidade de múltiplos modos de doação subjetiva, o noema, o X idêntico e vazio de múltiplas visadas, perspectivas subjetivas. Vê-se que a compreensão do idealismo transcendental de Husserl está diretamente ligada ao conceito de constituição. Ligação que pode ser observada nas palavras do próprio Husserl no famoso $\int 41$ das Meditações cartesianas que traz como título "A autêntica autoexplicitação fenomenológica do ego cogito como 'Idealismo transcendental"':

\begin{abstract}
Tudo o que é para esse ego é algo que se constitui nesse próprio ego e, mais ainda, que todo e qualquer tipo de ser - e, dentro disso, aquele que se caracteriza como transcendente em algum sentido - tem a sua constituição particular. A transcendência, em todas as suas formas, é um caráter de ser imanente, que se constitui no interior do ego. Todo sentido que se possa conceber, todo ser concebível, chame-se ele imanente ou transcendente, cai no domínio da subjetividade transcendental, enquanto constituinte de sentido e ser (HUSSERL, 2013, p. 122; HUSSERL, 1950, p. 117).
\end{abstract}

Ao se direcionar um olhar atento à passagem supracitada, pode-se observar ao menos três características fundamentais do idealismo transcendental proposto por Husserl: 1) tudo o que é para a consciência, todo sentido e ser, é constituído por uma realização (Leistung) sua (podendo ser essa realização tanto ativa como passiva); 2) não só a imanência, mas também a transcendência é constituída na e pela consciência; 3) não há um "fora" da subjetividade transcendental, ou seja, a subjetividade 
transcendental traz em si o mundo como "fenômeno de existência", nada há para fora ou para além dela.

Tendo apresentado o seu idealismo transcendental-fenomenológico como uma egologia transcendental, um constante processo de autoexplicitação da subjetividade transcendental, pode-se observar que a primeira formulação do problema de intersubjetividade é dada por Husserl mediante o desafio de se compreender o modo próprio de doação do alter ego a partir de uma análise dos processos de constituição do ego transcendental, sem compreender o alter ego como um mero objeto mundano, mas compreendendo-o como Outro ego transcendental constituidor de sentido e ser.

\footnotetext{
Mesmo neste olhar fugaz para o que em nós - em mim, o ego meditante - constitui-se como mundo, como universo de ser em geral, não podemos, naturalmente, evitar pensar nos outros e nas suas constituições. Por meio das constituições alheias, que se constituem no meu próprio ego, constitui-se para mim o mundo comum para todos nós (HUSSERL, 2013, p. 125-126; HUSSERL, 1950, p. 120).
}

Vê-se agora que o que motiva a investigação husserliana sobre a intersubjetividade não é nenhum questionamento empírico, mundano sobre a existência real dos Outros egos, mas sim uma questão aberta no interior de seu próprio idealismo transcendental. Tal questão refere-se à compreensão do modo como o ego transcendental constitui o Outro como sujeito transcendental e é também constituído pelo outro como sujeito transcendental. Relacionada diretamente a esta questão está a questão de apresentar uma fundamentação ao conhecimento válido universalmente, pois o mundo co-constituído pelos diversos egos é um e mesmo mundo, o mundo comum válido para todos.

\section{A teoria transcendental da experiência do Outro e a objetividade do mundo}

A elaboração de uma teoria transcendental da experiência do Outro, ocupa, de fato, um lugar central na fenomenologia husserliana, porquanto consiste no primeiro passo de um caminho descritivo que conduz a uma compreensão derradeira da intersubjetividade transcendental e com isso a resolução das dificuldades relativas ao estatuto transcendental da objetividade do mundo, pois tal teoria tem tanto o objetivo 
de resolver o problema do aípara mim (Für mich da) do Outro como o de, a partir desta solução, apresentar uma explicitação última do aí para qualquer um (Für jedermann da) em que consiste o mundo objetivo. Nas palavras de Husserl: “[...] o alcance de uma tal teoria é muito maior do que parece à primeira vista, dado que ela também conjuntamente funda uma teoria transcendental do mundo objetivo" (HUSSERL, 2013, p. 130; HUSSERL, 1950, p. 124) ${ }^{1}$.

Com o objetivo de realizar uma plena elucidação das camadas constitutivas da experiência do alter ego Husserl propõe a realização de um recurso metodológico necessário à consecução desta tarefa: a chamada redução à esfera de propriedade (Eigenheit). Tal redução consiste em, desde o solo da esfera do eu transcendental, realizar um exercício de abstração de tudo aquilo que não me pertence como próprio, ou seja, tudo aquilo que me é alheio ${ }^{2}$. O que deve ser abstraído é tudo aquilo que me é estranho (Fremd), aqui também incluído tudo aquilo que diz respeito à subjetividade alheia (o Outro como alter ego e o que deriva disso, como os objetos de cultura e a objetividade de um mundo compartilhado intersubjetivamente), ou seja, do fenômeno transcendental "mundo", é retirada abstrativamente a camada de sentido fundada que remete à constituição intersubjetiva.

Para evitar qualquer equívoco, faz-se necessário aqui esclarecermos mais detidamente em que consiste e qual é solo em que é realizado esse exercício de redução a esfera de propriedade. É importante notar que essa redução situa-se no interior da esfera estritamente transcendental da consciência ${ }^{3}$. Esfera esta que compreende tanto a imanência em sentido estrito, a imanência primária (a esfera dos

\footnotetext{
${ }^{1}$ Conferir também a passagem em que Husserl expressa que, em sentido alargado, uma autoexplicitação do ego mostra "como o ego constitui em si, em virtude deste seu ser próprio, também o outro, o objetivo e, em geral, tudo o que para ele tem validade de ser enquanto não eu o eu" (HUSSERL, 2013, p. 124; HUSSERL, 1950, p. 118).

2 "Enquanto assumo a atitude transcendental, procuro, primeiro que tudo delimitar o próprio-amim no interior do meu campo de experiência transcendental. Ele é, di-lo-ei em primeiro lugar, o não alheio" (HUSSERL, 2013, p. 133; HUSSERL, 1950, p. 126).

3 "A exclusão temática das realizações constitutivas da experiência do alheio e com isso de todos os modos de consciência referidos ao alheio, não quer apenas dizer a epoché fenomenológica a respeito da ingênua validade de ser do que me é alheio, tal como a de todos os objetos que, ingênua e diretamente, são para nós. Porque está e sempre continua pressuposta a atitude transcendental, segundo a qual tudo que antes fora diretamente para nós um ser é tomado exclusivamente como fenômeno, como um sentido visado que se confirma, puramente tal como adquiriu e adquire para nós sentido de ser, enquanto correlato de sistemas constitutivos que há de desvendar" (HUSSERL, 2013, p. 133; HUSSERL, 1950, p. 126).
} 
atos da consciência), como a transcendência imanente (imanente Transzendenz) (esfera dos modos de aparência dos objetos, ou seja, a esfera dos objetos entendidos como fenômenos) e também a esfera pré-imanente passiva da consciência (a esfera das afecções originárias (Urbyle) que passivamente fluem no fluxo absoluto da consciência constitutiva do tempo). É desta segunda camada do transcendental que, no exercício da redução à esfera de propriedade, se abstrai tudo aquilo que se refere ao que é alheio para o ego que pratica a redução, a saber, tudo aquilo que se refere ao Outro eu e ao mundo constituídos objetivamente, ou seja, todos os modos de consciência, os modos de aparências dos objetos, as visadas intencionais, numa palavra, todos os fenômenos que estão vinculados ao alheio (o Outro eu e o mundo objetivo efetivamente constituídos). No entanto, Husserl não cansa de nos dizer que é unicamente por razões metodológicas que a "operatividade sintética (a efetividade do alheio para mim) deve permanecer tematicamente excluída” (HUSSERL, 2013, p. 132; HUSSERL, 1950, p. 125). Assim, é importante estar claro que Husserl propõe o recurso metodológico de redução a esfera de propriedade e a suspensão de tudo o que há de alheio na esfera transcendental, unicamente para possibilitar um acesso primeiro ao que é próprio ao ego que pratica a redução e em seguida a que lhe é alheio, em especial ao Outro alter ego surpreendido então em seu caráter estritamente fenomenológico e transcendental.

Resta-nos, então, perguntar o que exatamente resta deste processo de redução abstrativa em que consiste a redução à esfera de propriedade? Husserl nos diz que é justamente o "fenômeno mundo" entendido como "natureza primordial" (primordinale Natur) — ou ainda, "mundo primordial" (primordinale Welt) — que me pertence e que deve ser distinguida da natureza pura e simples, ou seja, a natureza objeto de suas ciências. O que resta é, assim, uma "natureza" que consiste na "minha vinculação" própria com o mundo. Nas palavras de Husserl: "por meio dessa peculiar separação abstrativa de sentido do alheio, retivemos ainda um tipo de 'mundo', uma Natureza reduzida à propriedade (Eigenheit), um eupsicofísico como um corpo próprio (Leib), uma alma (Seele) 
e um eu pessoal, inserido nessa Natureza por meio do corpo próprio corpóreo (körperlich Leib)" (HUSSERL, 2013, p, 136; HUSSERL, 1995, p. 129).

O fenômeno corpo próprio (Leib) permanece como estrato noemático que resiste ao processo de redução à esfera da propriedade (Eigenheit). Ao considerar o corpo próprio como resíduo originário da redução à esfera da propriedade do ego (corpo que é aí entendido como um corpo próprio (Leib) vivo, animado e orgânico e não como mero corpo físico (Körper), estático, inanimado) ${ }^{5}$ Husserl destaca que a relação constitutiva do ego transcendental com o mundo se dá primariamente como experiência sensível do corpo próprio (Leib) que se realiza de diferentes modos em diferentes campos de sensações (como do tato, do olfato, da visão, etc.). "Percebo com as mãos, tateando cinestesicamente, do mesmo modo que olhando cinestesicamente, percepciono com os olhos, etc., e posso a todo tempo percepcionar, pois estas cinesteses dos órgãos transcorrem no eu faço e estão submetidos ao meu eu posso" (HUSSERL, 2013, p. 135; HUSSERL, 1950, p. 128).

Tem-se, assim, que é a partir do corpo próprio (Leib) que o ego transcendental se reconhece originariamente como uma mônada ${ }^{6}$ enquanto unidade do que me é próprio, do que é o meu ser concreto reduzido transcendentalmente. A partir daí, por meio da semelhança entre o corpo próprio do eu e o corpo próprio de outrem que aparece no campo perceptivo do ego, ocorre uma aperepşão analógica (analogische Apperzeption), na qual o sentido da unidade psicofísica do eu é transferido ao Outro, que, então, é constituído como um alter ego. Deste modo, "só na medida em que apareço corporalmente no mundo pode um outro corpo desse mundo emergir para mim como corpo de um outro sujeito, e eu próprio para ele enquanto sujeito corporal numa reciprocidade fechada" (ALVES, 2008, p. 347).

\footnotetext{
${ }^{4}$ Optou-se por traduzir Leib por corpo próprio diferentemente da tradução de Pedro Alves desse conceito como soma. Para manter a coerência com o restante do texto substituímos na tradução de Pedro Alves soma por corpo próprio.

${ }^{5}$ Observa-se aqui que Leib (corpo próprio) refere-se à transcendência imanente, a esfera pura da consciência, dos fenômenos e intencionalidades, já Körper (corpo físico) refere-se à transcendência objetiva. Körper consiste assim na noção de corpo estudada pelas ciências como física, biologia e psicologia.

${ }^{6}$ Mônada, conceito que Husserl toma emprestado de Leibniz, é entendido aqui como a plenitude concreta do eu que "compreende a inteira vida de consciência, efetiva e potencial" (HUSSERL, 2013, p. 107; HUSSERL, 1950, p. 102).
} 
O processo intencional de "apercepção analógica" que funda a experiência do Outro é caracterizado por Husserl como um emparelhamento (Paarung). Alves expressa com clareza em que consiste este processo de emparelhamento intencional.

\begin{abstract}
O emparelhamento é um processo geral da gênese passiva. Ele designa esse fenômeno pelo qual um conteúdo reenvia para um outro segundo uma síntese de analogia. Aplicado à questão da intersubjetividade, o emparelhamento circunscreve o fenômeno primitivo da consciência de um outro sujeito. Aí onde a percepção de simples corpos no mundo circundante é o lugar de uma transposição (Übertragung) da minha própria experiência somática dada na introcepção, aí se verifica, também, um fenômeno singular que é, digamos, a dimensão mais primitiva (mas não a única) da consciência de um outro sujeito - esse corpo diante de mim, dado num fluxo de simples percepções, torna-se lugar de apresentação (Appräsentation) de uma outra realidade psicossomática que é apreendida por analogia com a experiência originária de mim próprio" (ALVES, 2008, p. 347)
\end{abstract}

No entanto, é importante observar, que na experiência do Outro, este nunca se apresenta, nunca está diante de nós "em pessoa" (Leibhaft), pois não é aquilo que pertence a sua essência própria que chega a doação originária. Se fosse assim, se o que é próprio e essencial ao Outro estivesse disponível a mim de um modo direto, então, o Outro seria apenas um momento da minha essência própria e em conclusão ele e eu seríamos o mesmo. Deste modo, faz-se necessário que a intencionalidade da apercepção analógica que constitui a experiência do Outro se dê de um modo mediato e não direto.

O que é originariamente inacessível na experiência do Outro é a doação plena de sua esfera de propriedade. Pois se o ego apreendesse plenamente a esfera de propriedade do Outro, ele coincidiria com esse Outro. É por isso que a experiência do Outro sempre se dá num processo de apercepção por analogia, por semelhança. Apercepção que Husserl constantemente nos diz que não coincide com nenhuma “inferência por analogia", pois "apercepção não é inferência, não é um ato de pensamento” (HUSSERL, 2013, p. 149; HUSSERL, 1995, p. 141). Tal apercepção se dá somente como uma instituição originária (Urstifung) em que se constitui, por vez primeira, um objeto com o sentido do semelhante.

\title{
O caráter passivo-associativo do emparelhamento (Paarung) e suas consequências para a constituição da intersubjetividade transcendental
}


Faz-se necessário, ainda, para uma compreensão aprofundada da experiência do Outro, realizar uma análise mais detida sobre o componente associativamente constituinte do emparelhamento (Paarung) que constitui a experiência do Outro. O emparelhamento consiste num processo da síntese passiva que Husserl denomina associação (Assoz̧iation). Uma síntese de associação emparelhante ocorre quando no campo da pura passividade, esfera em que não há nenhuma realização (Leistung) ativa do eu, dois elementos são intuitivamente dados na unidade de uma consciência, de um modo que tais elementos engendram, mutuamente por meio de uma motivação passiva, uma unidade de semelhança que os constitui como um par (Paar $)^{7}$. Dá-se, assim, uma "transposição intencional" em que

\begin{abstract}
os elementos que se emparelham se tornam conscientes ao mesmo tempo e com destaque; visto ainda de mais perto, encontramos um evidente despertar-se mútuo, um mútuo deslocamento e um cobrir-se de cada um com o sentido objetivo do outro. Este recobrimento pode ser total ou parcial; ele tem cada caso, a sua gradatividade, sendo a igualdade o caso-limite" (HUSSERL, 2013, p. 151; HUSSERL, 1950, p. 142).
\end{abstract}

Como resultado deste recobrimento, realiza-se nos parelhas uma transferência de sentido, ou seja, a apreensão, de um elemento em conformidade com o sentido do outro, tanto quanto momentos de sentido realizados naquilo que é experienciado não anulem esta transferência na consciência do Outro.

No caso da associação e apercepção do alter ego através do ego, esta realiza-se por vez primeira quando o Outro surge no meu campo perceptivo, dá-se aí um emparelhamento originário em que o Outro é constituído passivamente não como mero corpo físico semelhante ao meu, mas como um Outro corpo próprio, como um Eu primordial, um outro Eu transcendental que co-constitui mundo na esfera do ali.

O Outro é apercebido apresentativamente como eu de um mundo primordial ou como uma mônada em que o seu corpo próprio é originariamente constituído e experienciado no modo do aqui absoluto, precisamente como centro funcionante do seu governo. Por conseguinte, nesta apresentação do corpo entrando na minha esfera monádica no modo do ali, que é apercebido como corpo somático alheio, como corpo próprio do alter ego, está indicado o mesmo corpo no modo do aqui, como aquilo que o outro experiencia na sua esfera monádica. Isto, porém, concretamente com o todo da intencionalidade constitutiva que este modo de doação nele opera (HUSSERL, 2013, p. 155; HUSSERL, 1995, p.146).

\footnotetext{
${ }^{7}$ Se houver mais de dois elementos dados, constitui-se um grupo fenomenalmente unitário, uma pluralidade, fundada em emparelhamentos singulares.
} 
Se o ego tem sempre o seu aqui como um centro de um mundo primordial orientado em seu redor e se o Outro e seu corpo tem sempre o modo do ali, o que o processo de emparelhamento revela é que o Outro também tem um aqui absoluto, um centro funcionante de sua própria esfera monádica. Assim, é como mônada que o Outro ego se apresenta no emparelhamento. O ego emparelhado é também um ego transcendental singularizado em sua mônada individual. Alter ego que é surpreendido enquanto tal como co-constituidor do mundo comum objetivo válido para qualquer um. Tem-se aí uma comunidade de mônadas que "constitui (na sua intencionalidade constituinte comunalizada) o mesmo e único mundo" (HUSSERL, 2013, p. 145; HUSSERL, 1950, p. 137).

Através dessa comunalização a subjetividade transcendental tem uma esfera intersubjetiva de propriedade, na qual ela constitui intersubjetivamente o mundo objetivo e, assim, ela é, enquanto nós transcendental, uma subjetividade para este mundo. Por fim, a intersubjetividade é ela própria constituída na idealidade como intersubjetividade aberta ao infinito, cujos sujeitos singulares estão dotados de sistemas constitutivos que se correspondem mutuamente e que são em conjunto concordantes. Por isso, pertence por essência à constituição do mundo objetivo uma harmonia de mônadas, "precisamente esta constituição particular nas mônadas particulares e, por conseguinte, também uma gênese decorrendo harmonicamente nas mônadas particulares" (HUSSERL, 2013, p. 146; HUSSERL, 1950, p. 138). Tem-se, assim, um principio de harmonia de nossos sistemas constitutivos mediante os quais as sínteses passivas e ativas que constituem os significados, formando para cada um de nós nosso mundo circundante, constituem um único e mesmo mundo: o mundo objetivo.

É, portanto, a sedimentação de sentido realizada pela comunidade de mônadas que sedimenta o sentido da unicidade do mundo monadológico e do mundo objetivo.

\begin{abstract}
Só pode haver, portanto, na realidade, uma única comunidade de mônadas, a de todas as mônadas, coexistentes, e, assim, apenas um único mundo objetivo, apenas um único tempo objetivo, apenas um único espaço objetivo, apenas uma única natureza; e tem de haver esta natureza uma e única, se, em geral, eu estou dotado de estruturas que impliquem o ser-com das outras mônadas (HUSSERL, 2013, p. 179; HUSSERL, 1950, p. 167).
\end{abstract}

É deste modo que a intersubjetividade transcendental, “o ser, primeiro em si”, serve de fundamento àquilo que há de objetivo no mundo. Intersubjetividade transcendental que consiste na totalidade das mônadas que se unem nas diversas 
formas de comunidade e comunhão. Deste modo, vê-se que para Husserl, tal como aponta Zahavi, "a forma de uma comunidade intermonádica é o verdadeiro ponto de partida de uma filosofia transcendental-constitutiva" (ZAHAVI, 1995 apud ALVES, 2008, p. 354) e "que só por uma abstração unilateral [...] se pode falar de um ego encapsulado numa consciência apodítica de si mesmo que torna o sentido alter ego em problema irresolúvel" (ALVES, 2008, p. 354). Vê-se que foi buscando explicitar a resolução derradeira de um suposto solipsismo existente no interior da sua fenomenologia que Husserl pôde desvelar em seus estratos constitutivos mais profundos um conceito originário e fundamental do campo transcendental de toda experiência: a intersubjetividade transcendental.

\section{Considerações finais}

Vê-se, agora, que é plenamente justificável defender a posição de que Husserl consegue apresentar uma compreensão coerente do estatuto transcendental da intersubjetividade no interior da sua fenomenologia. Tal posição pode ser sustentada ao se realizar uma análise atenta dos processos de redução fenomenológica propostos por Husserl. Para uma compreensão adequada sobre o estatuto transcendental da intersubjetividade em Husserl, faz-se necessário, portanto, uma análise atenta das diversas camadas da constituição (camadas da objetividade, da imanência, da transcendência imanente e do transcendental) descobertas pela realização dos processos de redução fenomenológica. Neste sentido, torna-se pertinente observar que as leituras sobre a questão da intersubjetividade transcendental em Husserl realizadas por filósofos como Sartre (1997), Schütz (1966; 1973), e em alguma medida também as realizadas por Merleau-Ponty (1991; 1994; 2006) e Ricoeur (2004), parecem, por vezes, não terem levado em conta a radicalidade das camadas mais profundas da constituição intencional e dos processos de redução fenomenológica propostos por Husserl. Já autores como Fink (1970; 1988; 1998), Mensch (1988), Zahavi (1995), Schnell (2007; 2010) e Depraz (1995; 2008) nos mostram como podemos compreender o estatuto transcendental da intersubjetividade proposto por Husserl ao acompanharmos todos os processos de redução fenomenológica e de descrição das camadas da constituição intencional. 
É importante observar também que os intérpretes Fink (1970; 1988; 1998) e Mensch (1988) consideram que uma compreensão derradeira e mais aprofundada do estatuto transcendental da intersubjetividade é apresentada somente em textos nos quais Husserl trata da relação entre intersubjetividade transcendental e os processos passivos da constituição da temporalidade, expostos em especial nos manuscritos de trabalho de Husserl Sobre a fenomenologia da intersubjetividade (Livros I, II e III) (HUSSERL, 1973a, 1973b, 1973c) e Textos tardios sobre a constituição do tempo (19291934) - Os Manuscritos C (HUSSERL, 2006). Concordo com tais autores quanto ao fato de que há um efetivo aprofundamento do estatuto transcendental da intersubjetividade realizado nas análises que Husserl faz sobre a relação entre a intersubjetividade transcendental e a constituição passiva da temporalidade, no entanto, buscou-se mostrar neste presente artigo (tal como também fazem as análises de Zahavi (1995), Schnell (2007; 2010) e Depraz (1995; 2008)) que podemos encontrar já no texto das Meditações Cartesianas uma explicitação do estatuto transcendental da intersubjetividade. Esta explicitação se dá justamente quando Husserl descreve o caráter passivo-associativo do emparelhamento que revela o Outro ego como um Outro centro funcionante, um Outro eu transcendental que co-constitui o mesmo e único mundo objetivo. Desta forma, vê-se que, se, de um lado, é nos textos que tratam da relação entre intersubjetividade transcendental e constituição temporal passiva que Husserl expõe o estatuto da intersubjetividade transcendental em todos os seus contornos, por outro lado, pode-se dizer também que em Meditações cartesianas já é exposto, mesmo que de um modo ainda preliminar, o estatuto transcendental da intersubjetividade no pensamento de Husserl.

Conclui-se, por fim, que a explicitação do estatuto transcendental da intersubjetividade não se contrapõe de maneira alguma ao idealismo transcendental fenomenológico proposto por Husserl, ao contrário, a compreensão do estatuto transcendental da intersubjetividade contribui para uma melhor e mais adequada caracterização do que é o campo do idealismo transcendental em Husserl, pois a intersubjetividade transcendental é um dos conceitos que melhor descreve o que é a esfera alargada da subjetividade transcendental. Sabe-se que a descrição da subjetividade transcendental é justamente a tarefa central do idealismo transcendental fenomenológico proposto por Husserl, idealismo que como vimos, não exclui, ao 
contrário, privilegia o tema da intersubjetividade como seu campo de pesquisa próprio e originário.

\section{Agradecimentos}

Agradeço ao CNPq que financiou esta pesquisa mediante concessão de Bolsa de Pós-doutorado Júnior (Processo 150024/2018-5).

\section{Referências}

ALVES, P. M. S. Empatia e ser-para-outrem: Husserl e Sartre perante o problema da intersubjetividade. Estudos e Pesquisas em Psicologia, Ano 8, n. 2, p. 334-357, 2008.

DEPRAZ, N. Transcendance et incarnation - Le statut de l'intersubjectivité comme alterité à soi chez. Husserl. Paris: Vrin, 1995.

DEPRAZ, N. Commentaire de la Cinquième Méditation (Deuxième partie: \49-62). In: LAVIGNE, J.-F. Les Méditations cartésiennes de Husserl. Paris: Vrin, 2008.

FINK, E. The Phenomenological Philosophy of Edmund Husserl and Contemporary Criticism. In: ELVETON, R. O. The Phenomenology of Husserl: Selected Critical Readings. Chicago: Quadrangle Books, 1970. p. 74-147.

FINK, E. Sixth Cartesian Meditation: The Idea of a Transcendental Theory of Method. Bloomington, Indiana: Indiana University Press, 1988.

FINK, E. Autres rédactions des Méditations Cartésiennes. Paris: Editions Jérôme Million, 1998.

HUSSERL, E. Cartesianische Meditationen (Husserliana I). Haag: M. Nijhoff, 1950.

HUSSERL, E. Zur Pbänomenologie der Intersubjektivität (Erster Teil) (Husserliana XIII). Hagg: Martinus Nijhoff. 1973a.

HUSSERL, E. Zur Phänomenologie der Intersubjektivität (Zweiter Teil) (Husserliana XIV). Hagg: Martinus Nijhoff. 1973b.

HUSSERL, E. Zur Phänomenologie der Intersubjektivität (Dritter Teil) (Husserliana XV). Hagg: Martinus Nijhoff. 1973c.HUSSERL, E. Späte Texte über Zeitkonstitution (1929-1934). Die CManuskripte (Husserliana Materialien VIII). Dordrecht: Springer Verlag, 2006.

HUSSERL, E. Meditações Cartesianas e conferências de Paris. Trad. Pedro M. S. Alves. Rio de Janeiro: Forense, 2013.

INGARDEN, R. On the Motives which led Husserl to Transcendental Idealism. Haag: M. Nijhoff, 1975.

MENSCH, J. R. Intersubjectivity and transcendental idealism. New York: State University of New York Press, 1988.

MERLEAU-PONTY. Signos. São Paulo: Martins Fontes, 1991. 
MERLEAU-PONTY, M. Fenomenologia da Percepscão. São Paulo: Martins Fontes, 1994.

MERLEAU-PONTY, M. Cursos da Sorbonne (1949-1952). São Paulo: Martins Fontes, 2006.

RICOEUR, P. A l'École de la phénoménologie. Paris: Vrin, 2004.

SARTRE, J-P. O Ser e o Nada. Ensaio de ontologia fenomenológica. Petrópolis: Vozes, 1997.

SCHNELL, A. Husserl et les fondements de la phénoménologie constructive. Grenoble: Millon, 2007.

SCHNELL, A. Intersubjectivity in Husserl's work. META: Research Hermenentics, Phenomenology, and Practical Philosophy v. 2, n. 1, p. 9-32, 2010.

SCHÜTZ, A. The Problem of Transcendental Intersubjectivity in Husserl. In: SCHÜTZ, A. Collected Papers III. Phaenomenologica, n. 22. Haag: M. Nijhoff, 1966. p 84-91.

SCHÜTZ, A. Sartre's theory of the Alter Ego. In: SCHÜTZ, A. Collected Papers 1. Phaenomenologica, n. 11. Haag: M. Nijhoff, 1973. p. 180-203.

SILVA, C. A. F. A carnalidade da reflexão: ipseidade e alteridade em Merleau-Ponty. São Leopoldo: Nova Harmonia, 2009.

ZAHAVI, D. Husserl und die transzendentale Intersubjetivität. Eine Antwort auf die sprachpragmatische Kritik. Dordrecht: Kluwer Academic Publishers, 1995. 